\title{
Spray coating of cellulose aerogel particles in a miniaturized spouted bed
}

\author{
Baldur Schroeter (1) - Velislava P. Yonkova • Monika Goslinska (i) • \\ Maike Orth (1) Swantje Pietsch (1) Pavel Gurikov (1) - Irina Smirnova (1) • \\ Stefan Heinrich
}

Received: 24 April 2021 / Accepted: 16 June 2021/Published online: 4 July 2021

(C) The Author(s) 2021

\begin{abstract}
Aim of this work is to apply protective and homogeneous shellac coating layers on the surface of hydrophilic open-pore cellulose aerogel particles with low densities $\leq 0.1 \mathrm{~g} / \mathrm{cm}^{3}$ and high specific surface areas in the range of $\sim 400-450 \mathrm{~m}^{2} / \mathrm{g}$ while keeping the aerogels' microstructure intact during processing. For this purpose, an innovative miniaturized spouted bed setup was used. Successful process settings for application of enclosed films on aerogel surfaces without intrusion of coating material into the pores were determined. Precise control of coating layer thickness in the range of 10-50 $\mu \mathrm{m}$ was achieved due to variation of coating solution amount without agglomeration and clogging events occurring during processing. Comparison of bulk densities and specific surface areas before and after coating proved the intactness of the porous structure. Coating of particles
\end{abstract}

Supplementary Information The online version contains supplementary material available at https://doi.org/10.1007/ s10570-021-04032-0.

\footnotetext{
B. Schroeter $(\bowtie) \cdot$ I. Smirnova

Institute for Thermal Separation Processes, Hamburg

University of Technology, Eißendorfer Straße 38,

21073 Hamburg, Germany

e-mail: baldur.schroeter@tuhh.de

V. P. Yonkova

Department of Chemical Engineering, University of Chemical Technology and Metallurgy, Kliment Ohridski

Boulevard 8, 1576 Sofia, Bulgaria
}

loaded with vanillin led to controlled release, enhancing release half-life times from 20 to $1600 \mathrm{~min}$. Overall, a successful strategy for coating of organic low-density aerogels was developed.

Keywords Aerogel $\cdot$ Cellulose $\cdot$ Spouted bed · Shellac coating $\cdot$ Drug release

\section{Introduction}

Aerogels are solid materials with a unique combination of properties such as high porosities, low densities and high specific surface areas $\left(S_{\mathrm{V}}\right)$. Their synthesis usually involves gelation, solvent exchange and supercritical drying steps (García-González et al. 2011). Besides many other applications, aerogels are suitable as tailorable carrier matrices for flavors and drugs, since they enable the targeted release of the

\footnotetext{
M. Goslinska $\cdot$ M. Orth $\cdot$ S. Pietsch $\cdot$ S. Heinrich Institute of Solids Process Engineering and Particle Technology, Hamburg University of Technology, Denickestraße 15, 21073 Hamburg, Germany

P. Gurikov

Laboratory for Development and Modelling of Novel Nanoporous Materials, Hamburg University of Technology, Eißendorfer Straße 38, 21073 Hamburg, Germany
} 
components from the porous structure and offer high loading capacities (Smirnova and Gurikov 2017; Bian et al. 2020). Food- and pharma sectors demand properties such as biodegradability and biocompatibility for in vivo use, which are provided by biopolymeric materials like starch-, alginate- or cellulosebased aerogels which can e.g. be loaded with various active pharmaceutical ingredients (Ulker and Erkey 2014; Veres et al. 2018; Pantić et al. 2016; Mehling et al. 2009; Zeng et al. 2020). The particular suitability of cellulose aerogel matrices as drug delivery systems is rooted in the possibility to induce controlled and hierarchical porosities, their relatively high stability when brought into aqueous environment, high specific surface areas, and the flexibility of macroscopic shape control, which allows the production of spherical particles with defined sizes (Budtova 2019; Volkert et al. 2009; Liebner et al. 2009). Besides, cellulose is a cheap and abundant raw material.

However, some challenges for in vivo use of biopolymer aerogels as carriers arise if a long-term release of the active agent is targeted: due to the hydrophilic surface and the open pore structure of aerogels the penetration of moisture or reactive molecules into the inner part of the materials may cause damage of the pores during storage and lead to aging of encapsulated material. Moreover, the pores may undergo fast collapse when the materials are exposed to an aqueous environment. Finally, depending on the loading process and interaction between loading substance and aerogel surface, active substances may be loaded in an amorphous state in form of a thin layer into the matrix (García-González et al. 2011). The given points may result in a poor kinetic control and contribute to a burst release of substances from the inner part, which is mainly controlled by the collapse of the 3D-structure instead of desired slower diffusion processes (Ulker and Erkey 2014).

One possibility to address these issues is a hydrophobic post-modification of aerogel inner surfaces, which prevents or considerably slows down the penetration of water into the pores on the one hand, but changes the original surface reactivity on the other hand. Application of a protective coating to the aerogel outer surfaces is an alternative approach, which leaves the inner part unmodified and provides a physical barrier as a protection of the inner porous structure and encapsulants. In addition, external coatings provide the possibility to achieve enhanced control over the release profile by tailoring the coating properties, like layer thickness, $\mathrm{pH}$ - and temperature sensitivity. Therefore, the possibility to coat cellulose aerogel particles with protective polymer layers was investigated in this work.

Application of homogeneous coating to the surface of particles is usually carried out in spray coating processes, where moving particles are brought in contact with dispersed coating solutions. Spray coating is a complex process involving many simultaneous steps and process parameters to be optimized (Jones 1985). Specifically, the light weight and low density of aerogel particles have to be considered, since they result in a non-classical fluidization behavior, which may not be described adequately by classical Geldart-classification (Akgün and Erkey 2019). The open porous nature of aerogels may allow significant penetration of the solvent into the aerogel core, resulting in changes or destruction of the porous network, due to the high capillary forces, which occur during subsequent evaporative drying. To prevent this, solidification of the polymer layer has to be faster than penetration of the solution into the pores (Alnaief et al. 2012).

Spouted bed systems are promising setups in this regard since they enable extreme fast heat and mass transfer between gas and particle phases. Aerogel particle fluidization dynamics and spray coating in spouted bed systems have already been described in work, which focused on simulation and mechanical aspects of the process, determining the important process parameters to keep particle macroscopic shape intact during processing (Antonyuk et al. 2012, 2013). Besides particle intactness, two additional requirements can be formulated for spray coating of aerogels in spouted bed systems: (1) The coating materials should be applied in a homogenous manner and defined layer thickness. (2) The inner pore structure has to be preserved to keep the aerogel functionality intact. Especially the second point is not easy to quantify via characterization methods. The shrinkage behavior of silica and starch/alginate hybrid aerogels during coating processes with an aqueous suspension was investigated by Antonyuk et al. (2015) and Alnaief et al. (2012). They also several measures for the preservation of the porous structure from shrinkage were suggested. Since the direct coating with aqueous Eudragit ${ }^{\circledR}$ solution led to pore collapse, a double layer approach was necessary, wherein the particles were firstly coated with a melt, before being exposed to 
water born coating material (Alnaief et al. 2012). In this regard, measurements of specific surface area can provide a sensitive assessment of aerogel quality under varying operating conditions (Subrahmanyam et al. 2015). Goslinska et al. (2019) found a direct correlation between the decrease of specific surface area and amount of applied coating material, showing the intactness of the pores and quality of the coating layer. In the same work, ethanolic shellac solutions were used to coat micrometer-sized whey protein aerogel particles with an initial surface area of $207 \mathrm{~m}^{2} \mathrm{~g}^{-1}$, firstly creating coated, fully edible aerogels with intact porosity.

Shellac is a natural resin and is used for instance in commercially available modified atmosphere packaging systems (Sandhya 2010). The use of edible shellac coatings as barrier system has been documented since the beginning of the last century, e.g. for pharmaceuticals, confections, fruits and vegetables. A combination of hydrophobicity and biodegradability makes shellac a promising renewable material in formulations with cellulose. In addition, cellulose/shellac systems fulfill the regulations of American food and drug administration legislations on components for food contact materials (Hult et al. 2010).

In this work we aim to investigate the possibility to coat cellulose aerogels with shellac to protect the cellulose matrix from moisture and to enable an (edible) product suitable for long term release of active substances in aqueous surrounding.

Our strategy towards shellac coated cellulose aerogel particles involves the following steps (Fig. 1): (1) Synthesis of highly spherical cellulose aerogel particles with different particle sizes, densities and narrow size distributions. Sphericity of particles is an important factor with respect to the target application, since it brings benefits in terms of flowability, homogeneous heat- and mass transfer as well as for controlled release of encapsulants (Lee et al. 2013). (2) Spray coating of cellulose aerogel particles with ethanolic shellac solutions in a miniaturized spouted bed setup under variation of process parameters like shellac content in coating solution and the ratio of a spray solution to the bed mass in order to determine successful process conditions. (3) Characterization of coating properties, coating-pore interaction and aerogel microstructure. (4) Quantification of drug delivery properties by determination of release kinetics from particles loaded in supercritical carbon dioxide.

\section{Materials and methods}

Materials and experimentation

\section{Preparation of coagulation bath solutions}

Different coagulation bath solutions consisting of diluted (33 wt.\%) aqueous sulfuric acid $\left(\mathrm{H}_{2} \mathrm{SO}_{4}\right.$, Merck Millipore, Emsure ${ }^{\circledR}$ ), and a mixture of ethyl acetate (EtAc Carl Roth GmbH \& Co. KG), trichloromethane $\left(\mathrm{CHCl}_{3}\right.$, Carl Roth $\left.\mathrm{GmbH} \& \mathrm{Co} . \mathrm{KG}\right)$ and acetic acid $\left(\mathrm{CH}_{3} \mathrm{COOH}\right.$, Carl Roth $\left.\mathrm{GmbH} \& \mathrm{Co} . \mathrm{KG}\right)$ were used to induce the coagulation of the cellulose solutions. EtAc and $\mathrm{CHCl}_{3}$ ratios were kept constant at equal mass ratios, $\mathrm{CH}_{3} \mathrm{COOH}$ ratio was $10 \mathrm{wt} \%$ regarding the overall mass.

\section{Preparation of cellulose aerogel particles}

A quantity of 10 or $30 \mathrm{~g}$ microcrystalline cellulose type II (JRS Pharma GmbH \& Co. KG, Vivapure ${ }^{\circledR}$, 101) was dispersed in $200 \mathrm{~g}$ demineralized water and left for swelling at $5{ }^{\circ} \mathrm{C}$ for at least $30 \mathrm{~min} .38 \mathrm{~g}$ of $\mathrm{NaOH}$ (Merck KGaA) were dissolved in 232 or $252 \mathrm{~g}$ demineralized water and cooled to $-9{ }^{\circ} \mathrm{C}$. The swollen cellulose/water dispersion was added to the $\mathrm{NaOH}$ solution and stirred $(500 \mathrm{rpm})$ at $-9{ }^{\circ} \mathrm{C}$ for two hours in a double jacket glass reactor with a volume of $500 \mathrm{~mL}$ to achieve a homogeneous cellulose solution with a cellulose content of 2 or $6 \mathrm{wt} . \%$. The solutions were stored at $5{ }^{\circ} \mathrm{C}$ for a maximum of $24 \mathrm{~h}$ and used for further processing. Cellulose particles with particle diameter $d_{\text {particle }}<2 \mathrm{~mm}$ were produced via jet cutting, following the procedure described by Schroeter et al. (2021). For production of particles with $d_{\text {particle }}>2 \mathrm{~mm}$, dripping method was applied. Cellulose solutions were extruded from tubes and syringes (diameters $=0.4-4.1 \mathrm{~mm}$ ) into the coagulation bath solutions $\left(3 \mathrm{~L}, 20^{\circ} \mathrm{C}\right)$. The distance between the syringe tip and the coagulation bath was kept small $(7 \mathrm{~cm})$ and coagulation solutions where gently stirred via magnetic stirrer during processing. Cellulose solutions were kept at a temperature of $5{ }^{\circ} \mathrm{C}$ in order to avoid thermal gelation of cellulose during the runs prior to getting in contact with the coagulation bath. Two compositions of the coagulation bath were employed: with aqueous sulfuric acid and with mixtures of EtAc/ $\mathrm{CHCl}_{3} / \mathrm{CH}_{3} \mathrm{COOH}$. A maximum of $1 \mathrm{~L}$ cellulose solution per $3 \mathrm{~L}$ of coagulation solution 


\section{1) Aerogel synthesis}
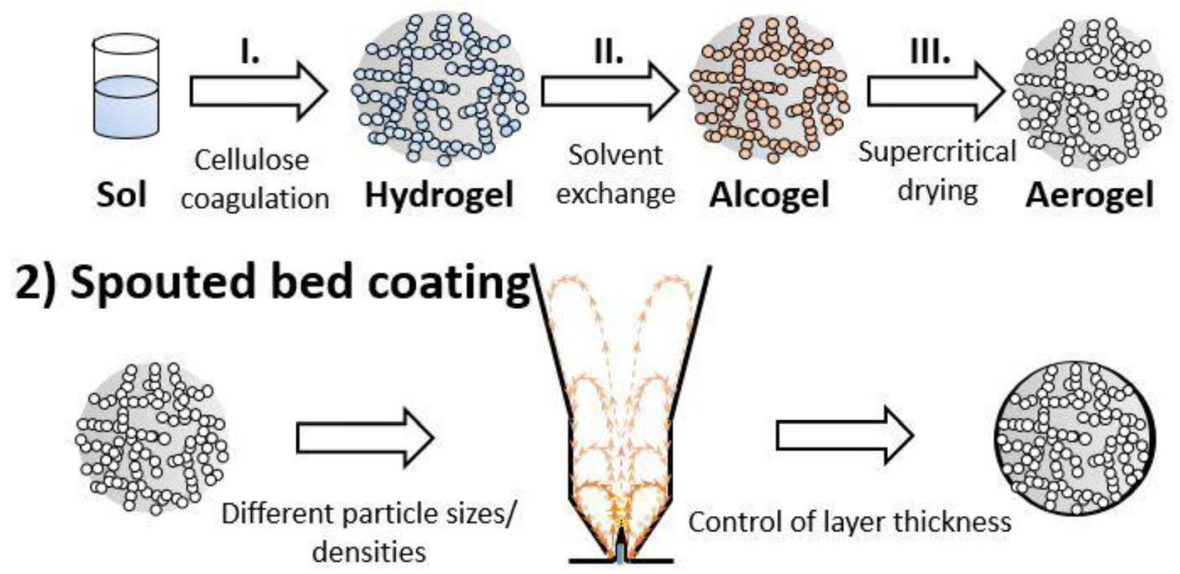

3) Supercritical impregnation \& release
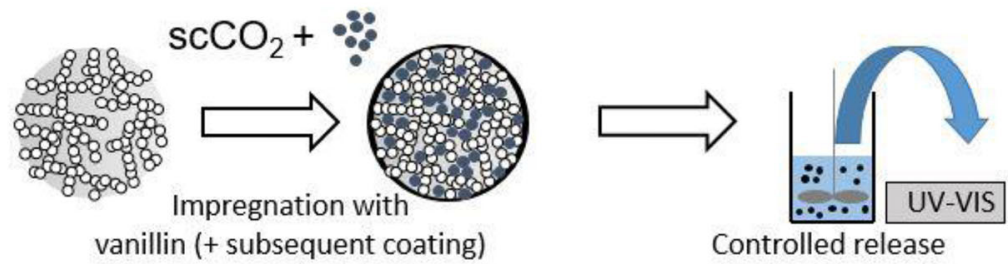

Controlled release

Fig. 1 Overall scheme of this work

was used in each run. Hydrogel particles were collected with a mesh. Hydrogel particles produced in the aqueous sulfuric acid bath were washed with demineralized water until a $\mathrm{pH}$ value of 2 was reached in the water phase, while hydrogel particles coagulated in $\mathrm{EtAc} / \mathrm{CHCl}_{3} / \mathrm{CH}_{3} \mathrm{COOH}$ were directly transferred to the solvent exchange step. Solvent exchange was carried out by immersion of the resulting hydrogel particles in 99.9 wt.\% ethanol until a minimum final concentration of $98.0 \mathrm{wt}$ \% ethanol inside the hydrogel particles was reached (controlled by density measurements, Anton Paar, DMA 4500 M). Approximately $7 \mathrm{~L} \mathrm{EtOH}$ per liter hydrogel were used. After the solvent exchange, the particles were sealed into a filter paper bag and placed into a high pressure autoclave with an overall volume of $3.9 \mathrm{~L}$ for supercritical drying with $\mathrm{CO}_{2}$. The supercritical drying was performed at a temperature of $60{ }^{\circ} \mathrm{C}$ and pressure of 120 bar. A continuous flow of $\mathrm{CO}_{2}$ (flow rate $=120-140 \mathrm{~g} / \mathrm{min}$ ) was set through the autoclave until complete extraction of ethanol was achieved after $4 \mathrm{~h}$. The dried particles were collected after slow depressurization (1 bar/min) of the autoclave. Dried particles were stored in sealed tubes $(25 \mathrm{~mL}$, Sarstedt) in a desiccator over calcined silica gel prior to analysis.

Specific surface area and pore size distribution

Low temperature $\mathrm{N}_{2}$ adsorption-desorption analysis was used to investigate microstructural properties of the aerogels (Nova 3000e Surface Area Analyzer, Quantachrome Instruments, Boynton Beach, USA). An overall sample mass of $20-30 \mathrm{mg}$ was used for each analysis, which corresponds to 6-20 intact particles per measurement, depending on the overall particle size. The specific surface area was determined using the BET (Brunauer-Emmett-Teller) method (single determinations). The standard error of $5.5 \%$ for the individual BET-results was estimated from the average error of four double determinations. The pore volume and mean pore diameter were estimated by the BJH (Barrett-Joyner-Halendia) method and applying approximation of cylindrical pores, respectively. All 
samples were degassed under vacuum at $60{ }^{\circ} \mathrm{C}$ for $6 \mathrm{~h}$ prior to analysis.

\section{Bulk density}

A container with a volume of $12.5 \mathrm{~cm}^{3}$ was completely filled with dry aerogel particles. The full as well as the empty container were weighted using an analytical scale (Excellence Plus XP, Mettler Toledo) and the bulk density $\left(\rho_{\text {bulk }}\right.$ ) was calculated as a ratio of the particles' mass and the known volume of the container. All measurements were carried out in triplicate.

\section{Preparation of shellac solutions}

Coating solutions with three different shellac concentrations $c_{\text {shellac }}$ were prepared as follows: $37.5-75.0 \mathrm{~g}$ of shellac flakes (SSB56 Pharma FL) were mixed continuously with $175.0-212.5 \mathrm{~g}$ of pure ethanol (Table 1). After dissolution of the shellac flakes, $1.2 \mathrm{~g}$ of a red or blue food dye (Ruth $\mathrm{GmbH}$, strawberry coloured, patent blue V) was added to the solution to enable the visual evaluation of the coating procedure during the process.

\section{Coating of cellulose aerogel particles in a miniaturized spouted bed}

A miniaturized conical-cylindrical spouted bed was used for the coating process of the aerogel particles with the shellac-ethanol solution. The process chamber, the expansion zone, and the lower part of the relaxation zone of the spouted bed are conical and the upper part of the relaxation zone is cylindrical (Fig. 2).

A charge of $4.0-18 \mathrm{~g}$ (depending on the bulk densities for particles of different composition and size) of aerogel particles were introduced into the process chamber and the fluidization was started. The process conditions for all experiments are shown in

Table 1 Recipes for preparation of shellac coating solutions

\begin{tabular}{llrr}
\hline Material $(\mathrm{g})$ & \multicolumn{3}{c}{$c_{\text {shellac }}($ wt.\%) } \\
\cline { 2 - 4 } & 15 & 20 & 30 \\
\hline Shellac flakes & 37.50 & 50 & 75 \\
Ethanol $(\geq 99.8 \%)$ & 212.5 & 200 & 175 \\
\hline
\end{tabular}

Table 2. The particles were fluidized with heated air at gas volume flow rates $\dot{V}_{\text {fluidisation }}$ between 1.2 and $5.1 \mathrm{~m}^{3} / \mathrm{h}$ and at a temperature of $80^{\circ} \mathrm{C}$ at underpressure conditions. The high gas velocities in the annular gap result in a turbulent jet in the middle of the process chamber taking along the particles. The gasparticle jet passes the conical expansion zone and enters the cylindrical relaxation zone, and as a result of the decrease of gas velocity due to the increasing diameter of the chamber, a fountain is formed. The particles drift toward the walls of the apparatus and slide back into the process chamber due to gravity and are then entrained by the jet again. Thus, the typical, circulating particle movement inside a spouted bed is formed (Goslinska et al. 2019; Rothberg et al. 2020).

The shellac/ethanol solutions $\quad\left(c_{\text {shellac }}=15-\right.$ 30 wt.\%) were filled into a syringe and different quantities of the spraying solution $(8-50 \mathrm{~mL})$ were injected into the apparatus during the experiments via a syringe pump (Legato 270, World Precision Instruments Germany GmbH, Friedberg, Germany) with a spraying rate of $0.5 \mathrm{~mL} / \mathrm{min}$ through a two-fluid nozzle (Model 970/3 S1, Düsen-Schlick GmbH, Germany, nozzle tip size: $0.5 \mathrm{~mm}$ ). The nozzle was installed in a bottom-spray configuration. In order to obtain different ratios $r_{\mathrm{v} / \mathrm{m}}$ between the overall particle mass and amount of coating solution, the mass of particles $m_{\text {bed }}$ was kept constant at given reaction conditions and the quantity of the injected solution $v_{\text {spray }}$ was varied. To avoid the risk of elutriation of the particles the atomization air was kept at low flow rates $\left(\dot{V}_{\text {atomization }}=0.5-0.9 \mathrm{~m}^{3} / \mathrm{h}\right)$. At these spray air volume flows the formation of small droplets was still ensured. The droplets are spreading on the particle surfaces, ethanol evaporates and a shellac layer solidifies on the particle surfaces. Before the completion of the experiments, an additional $10 \mathrm{~min}$ post drying step (spouting without spraying) was applied to ensure the complete evaporation of the solvent.

\section{D laser scanning confocal microscopy}

The surface roughness is described by the arithmetical mean height $(\mathrm{Sa})$ of the surface and was measured via a 3D laser scanning confocal microscope VK-X160K (Keyence). Six measurements at $10 \times$ and six measurements at $100 \times$ magnification were performed for each sample. The taken images were evaluated using 


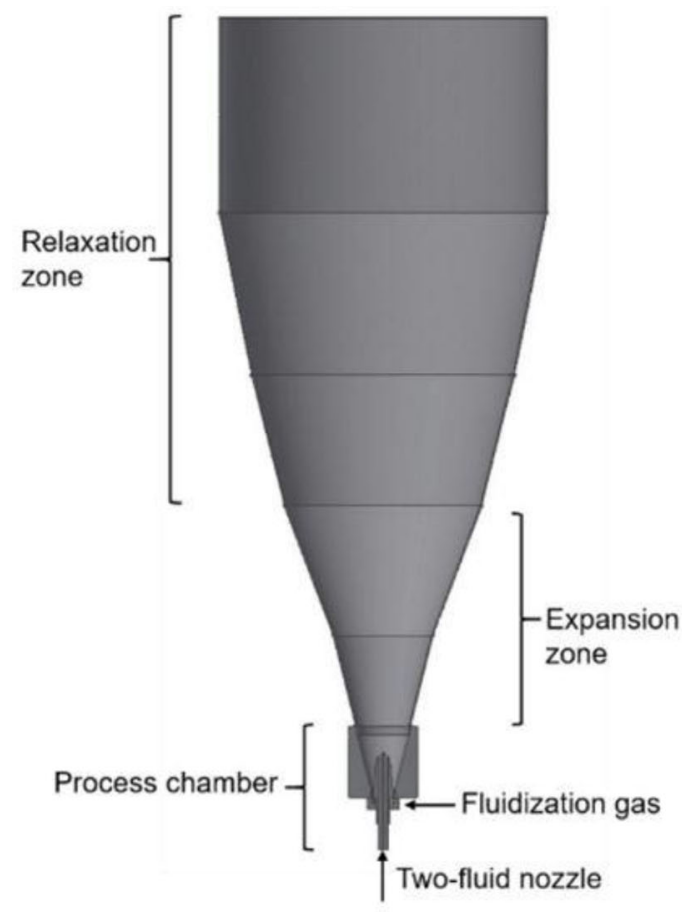

(a)

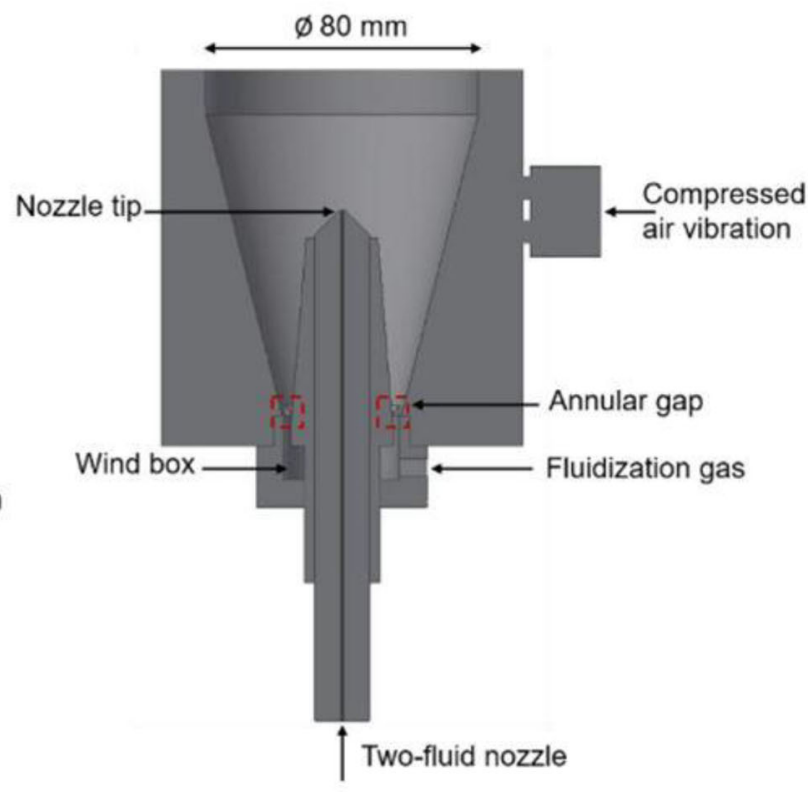

(b)

Fig. 2 Cross-section of the: a miniaturized spouted bed with a total height of $1.25 \mathrm{~m}$; $\mathbf{b}$ process chamber with annular gap for fluidization gas and two-fluid nozzle for coating solution

(gradient of process chamber wall: $12^{\circ}$ ). Reproduced from Rothberg et al. (2020) with permission

Table 2 Process parameters for coating experiments

\begin{tabular}{|c|c|c|c|c|c|c|c|}
\hline \multicolumn{2}{|c|}{ Particle size and composition } & \multicolumn{6}{|c|}{ Spray coating process parameters } \\
\hline$d_{\text {particle }}(\mathrm{mm})$ & $c_{\text {cell }}($ wt. $\%)$ & $m_{\text {bed }}(\mathrm{g})$ & $\dot{V}_{\text {fluidisation }}\left(\mathrm{m}^{3} / \mathrm{h}\right)$ & $\dot{V}_{\text {atomization }}\left(\mathrm{m}^{3} / \mathrm{h}\right)$ & $c_{\text {shellac }}($ wt. $\%)$ & $v_{\text {spray }}(\mathrm{mL})$ & $r_{\mathrm{v} / \mathrm{m}}(\mathrm{mL} / \mathrm{g})$ \\
\hline 1.01 & 6 & 18 & $1.8-3.6$ & $0.5-0.72$ & 20 & 36 & 2.0 \\
\hline 2.02 & & 12 & $2.4-4.5$ & $0.6-0.72$ & 20 & 24 & 2.0 \\
\hline 3.29 & & 10 & $3.9-5.1$ & $0.6-0.9$ & 30 & $10-35$ & $1.0-3.5$ \\
\hline $3.06^{\mathrm{a}}$ & & 8 & $3.9-5.1$ & $0.6-0.9$ & 20 & $4-32$ & $0.5-4.0$ \\
\hline 3.74 & & 10 & 5.1 & $0.6-0.9$ & 20 & 20 & 2.0 \\
\hline 4.37 & & 10 & 5.1 & 0.9 & 15 & $10-35$ & $1.0-3.5$ \\
\hline 4.37 & & 10 & 5.1 & 0.9 & 20 & $10-50$ & $1.0-5.0$ \\
\hline 3.18 & 2 & 4 & 1.8 & 0.6 & 20 & $8-20$ & $2.0-5.0$ \\
\hline
\end{tabular}

Constant process parameters: spray rate of coating solution $0.5 \mathrm{~mL} / \mathrm{min}$; temperature inside the process chamber $40{ }^{\circ} \mathrm{C}$, air inlet temperature $80^{\circ} \mathrm{C}$

${ }^{\mathrm{a}}$ Particles loaded with vanillin

the surface area tool of the MultiFileAnalyzer software (Keyence). To smooth the curvature caused by the spherical shape of the particles as well as signal noise and thus avoid aberrations in the roughness calculations, a sphere correction tool and filters were used in the software that neglect depressions and heights below 8 and above $80 \mu \mathrm{m}$. Through image analysis (Image J) of the laser microscope pictures the 


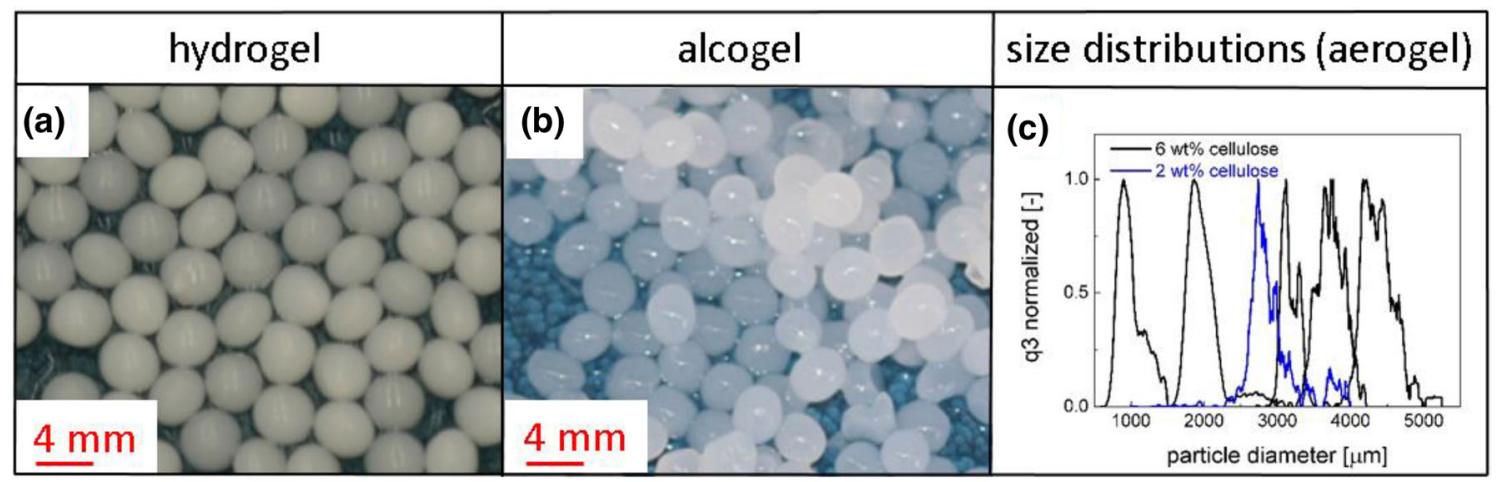

Fig. 3 a Hydrogel particles, $c_{\text {cell }}=6 \mathrm{wt} . \%$, $\mathbf{b}$ alcogel particles, $c_{\text {cell }}=2 \mathrm{wt} . \%$ and $\mathbf{c}$ particle size distributions of dry aerogels

coating layer thickness was determined and afterwards compared with the image analysis results of the scanning electron microscope images. For this purpose, respectively three coated particles were cut in half and six pictures at $20 \times$ and/or $100 \times$ magnifications of the two opposing sides of one half were taken. No differences resulting from the magnification lenses were noticed in the evaluation of the pictures.

\section{Scanning electron microscopy}

The surface properties and inner structure of the aerogels as well as the layer thickness of the shellac coating were characterized via scanning electron microscopy (SEM, Zeiss Supra VP55, Jena, Germany). The intact and cut particles were sputtered with a thin layer of gold (Sputter Coater SCD 050, BALTEC) before analysis was started. The measurements were carried out under high vacuum at an accelerating voltage of $2-5 \mathrm{kV}$.

\section{Image analysis of particles}

Size and shape of dry aerogel particles were determined with a Camsizer XT system (Retsch Technology) in free fall mode. All characterizations were carried out according to DIN 66141. As particle diameter $d_{\text {particle }}$ the calculated Sauter mean diameter was adopted:

$d_{\text {particle }}=\frac{1}{M_{-1,3}}=\frac{1}{\int_{x_{\min }}^{x_{\max }} x q_{3}(x) d x}$

where $x_{\min }$ is the particle size below which there are no particles in a given size distribution, $x_{\max }$ is the particle size above which there are no particles in a given size distribution, $q_{3}(x)$ is the volume (mass) distribution density, $M_{-1,3}$ is the complete first moment of a $q_{3}(x)-$ sample distribution. Particles' sphericity $S P H$ is given according to ISO 9276-6 as:

$S P H=\frac{4 \pi A}{P^{2}}$

where $P$ is the measured perimeter/circumference of a particle projection and $A$ is the measured area covered by a particle projection. For an ideal sphere $S P H$ is equal to 1 and for real samples lower than 1 . The polydispersity of the samples is given as the Span value based on volume:

Span $=\frac{x Q_{3}(90)-x Q_{3}(10)}{x Q_{3}(50)}$

with $x Q_{3}=Q_{3}$ values, where a given particle diameter $x$ is reached, based on volume.

\section{Supercritical impregnation}

Vanillin was used as an UV-Vis active and sublimable flavor encapsulant, which can be supercritically impregnated into the porous aerogel structure due to its good solubility in supercritical $\mathrm{CO}_{2}$ (Rojas-Ávila et al. 2016). For supercritical impregnation, aerogel particles were sealed in filter bags and transferred to an autoclave with an overall volume of $250 \mathrm{~mL}$, vanillin powder was placed in an open metal cup at the bottom of the autoclave. Particles with an initial diameter of $d_{\text {particle }}=3.29 \mathrm{~mm}$ and a cellulose content of $c_{\text {cell- }}$ $=6 \mathrm{wt}$. $\%$ were used. A weight ratio of aerogel:vanillin $=1.0: 1.5$ was used. Impregnation was carried out at a pressure of 125 bar and a temperature of $60{ }^{\circ} \mathrm{C}$ for $16 \mathrm{~h}$. The impregnated particles were collected 
after slow depressurization $\left(1 \mathrm{bar} \mathrm{min}^{-1}\right)$ of the autoclave.

\section{Release experiments}

Impregnated aerogel particles were placed in a beaker filled with $500 \mathrm{~g}$ demineralized water kept at a temperature of $30{ }^{\circ} \mathrm{C}$ and stirred at $200 \mathrm{rpm}$ with an overhead stirrer. Six to eight particles were used in each experiment. Samples of the water phase were taken periodically ( $2 \mathrm{~mL}$ each) and transferred to cuvettes (Hellma Analytics, 117-QS). The vanillin concentration was determined via UV-Vis-spectroscopy (Thermofisher Evolution 300) at a wavelength of $230 \mathrm{~nm}$. Sample solutions were returned to the beaker after determination of vanillin concentration.

\section{Results and discussion}

Production and properties of cellulose aerogel particles

Spherical cellulose aerogel particles with different densities were obtained by variation of coagulation baths compositions. Aqueous sulfuric acid based coagulation has been reported to be a successful and green way towards particles at higher cellulose content with high $\mathrm{SPH}$ and was therefore also used in this work for production for particles with $c_{\text {cell }}=6 \mathrm{wt} . \%$ (Schroeter et al. 2021). However, this method is not suitable at low cellulose contents of $1-3 \mathrm{wt} . \%$. For the production of particles with $c_{\text {cell }}=2 \mathrm{wt}$. $\%$ the method reported by Bian et al. was adapted and a coagulation bath consisting of $\mathrm{EtAc} / \mathrm{CHCl}_{3} / \mathrm{CH}_{3} \mathrm{COOH}$ was applied. At $c_{\text {cell }}=6 \mathrm{wt} . \%$, particles with five different diameters in the size range of $1.01-4.37 \mathrm{~mm}$ were produced, and at $c_{\text {cell }}=2 \mathrm{wt} . \%$ one particle size of $3.18 \mathrm{~mm}$ was set. Narrow particle size distributions $(S P A N=0.12-0.58)$ and highly spherical shapes $(S P H=0.91-0.96)$ were obtained for particles with $d_{\text {particle }}>2.00 \mathrm{~mm}$ produced by dripping method.

Slightly lower values of $S P H=0.86$ were obtained for particles with $c_{\text {cell }}=2 \mathrm{wt} . \%$, which can be attributed to partial breakage of some particles during shape analysis in the Camsizer XT system. All aerogels showed high specific surface areas $\left(428 \pm 35 \mathrm{~m}^{2} / \mathrm{g}\right)$ with no notable trend with respect to the coagulation conditions. Obtained surface areas are in the higher range for cellulose II aerogels and in good agreement with the previously reported results (Budtova 2019; Schroeter et al. 2021). In case of aerogels with $c_{\text {cell }}=2 \mathrm{wt}$. $\%$ the achieved surface area of $405 \mathrm{~m}^{2} / \mathrm{g}$ exceeds the values reported by Bian et al. (2020) by 39-61\%, who used freeze drying in the final processing step. This difference can be explained by the difference of applied drying techniques, since supercritical drying preserves the mesopores, while they are mainly lost during the freeze-drying leading to macroporous materials with significantly lower specific surface areas (Baudron et al. 2019).

Microstructure, density and surface roughness of the cellulose aerogel particles were found to be significantly dependent on the processing route and cellulose content (Table 3).

While differences in the bulk densities can be related to the different overall cellulose contents, structural and textural properties are most likely affected by the coagulation methods. The results of characterization of both the pore structure and the particle surface via SEM support the results given in Table 3 and allow more detailed insights into the structural properties of the materials. Aerogels with a cellulose content of $2 \mathrm{wt} . \%$ show an open macroporous and wavy surface (Fig. $4 a, b$ ). In addition, the porous network contains macro channels (Fig. 4c) with diameters of approx. 200-600 $\mathrm{nm}$ which reach up to the particles surface. In contrast, particles with cellulose content of $6 \mathrm{wt} . \%$ show a homogenous and smooth surface which contains no macropores (Fig. 4d, e), whereas homogeneous distributed mesopores with diameters $\leq 40 \mathrm{~nm}$ can be identified. The inner porous network appears denser compared to particles with lower cellulose content (Fig. 4f). In addition, a thin, dense layer in form of a skin is formed on the surface of particles coagulated in sulfuric acid, as also reported in previous works (Schroeter et al. 2021), while such layer could not be observed for particles coagulated in $\mathrm{EtAc} / \mathrm{CHCl}_{3} / \mathrm{CH}_{3} \mathrm{COOH}$.

Even though the mechanisms of acidic induced coagulation of sodium hydroxide based cellulose solutions are not completely understood up to now, differences of microstructure and surface properties may be attributed to solvent effects occurring during the hydrogel formation. While in aqueous sulfuric acid baths coagulation is controlled by one process (diffusion of water/acid mixture into the inner part of the 
Table 3 Properties of aerogels produced with different cellulose content and under different coagulation conditions

\begin{tabular}{llllll}
\hline$c_{\text {cell }}($ wt.\%) & Coagulation bath $(-)$ & $S \mathrm{a}(\mu \mathrm{m}) *$ & $d_{\text {pore }}(\mathrm{nm})$ & $v_{\text {pore }}(\mathrm{cc} / \mathrm{g})$ & $\rho_{\text {bulk }}\left(\mathrm{g} / \mathrm{cm}^{3}\right)^{*}$ \\
\hline 2.0 & EtAc/CHCl$/ \mathrm{CH}_{3} \mathrm{COOH}$ & $3.89 \pm 1.81$ & $8.65 \pm 0.05$ & $2.92 \pm 0.20$ & $4.10 \times 10^{-2} \pm 1.56 \times 10^{-3}$ \\
6.0 & Aqueous $\mathrm{H}_{2} \mathrm{SO}_{4}$ & $1.72 \pm 0.08$ & $13.7 \pm 0.07$ & $3.99 \pm 0.28$ & $1.07 \times 10^{-1} \pm 9.04 \times 10^{-3}$ \\
\hline
\end{tabular}

$d_{\text {pore }}$ is the average pore diameter, $v_{\text {pore }}$ is the pore volume

$*$ At $c_{\text {cell }}=6 \mathrm{wt} . \%$ : results for all different particle sizes used to calculate the average and standard deviation

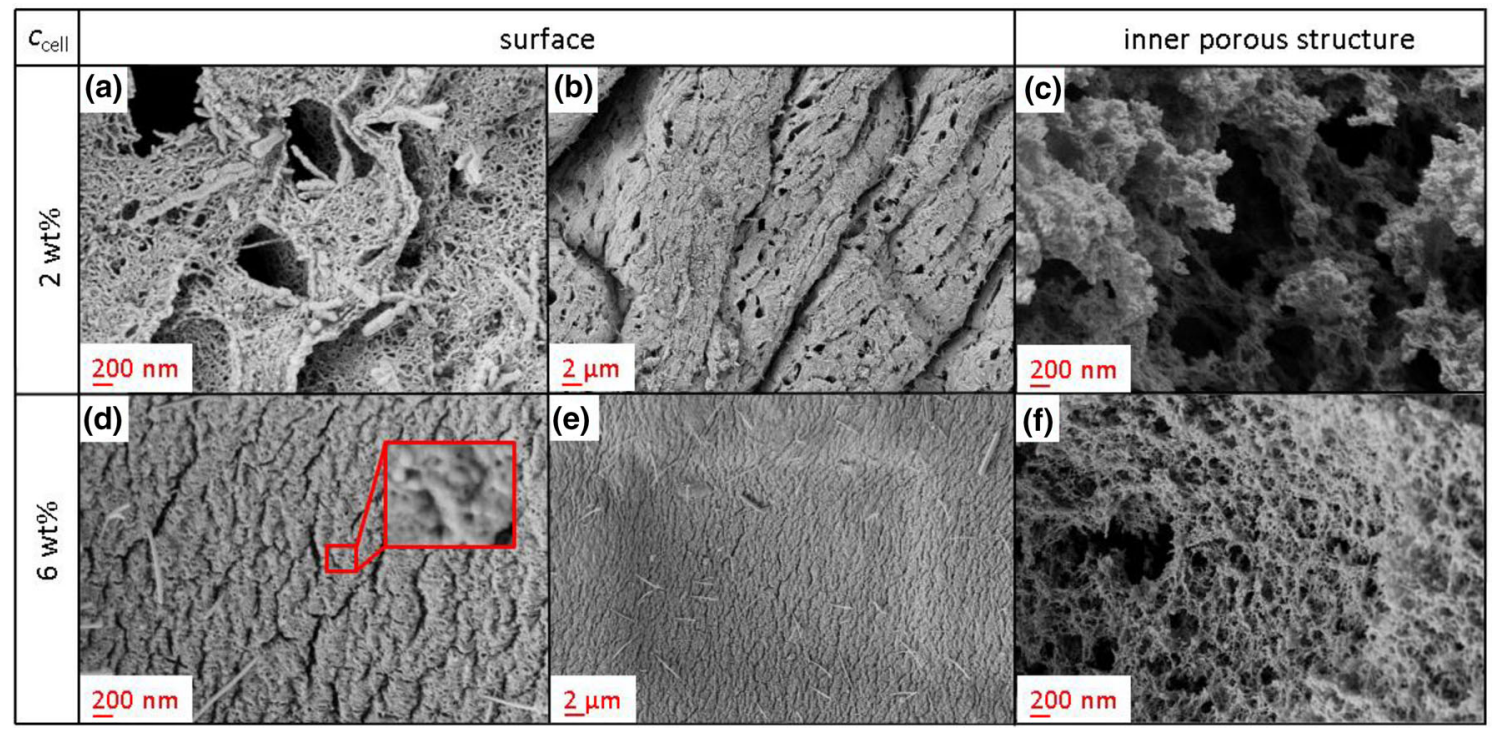

Fig. 4 SEM pictures of particles with different cellulose content. a, b Surface and $\mathbf{c}$ porous network at $c_{\text {cell }}=2$ wt. $\%$. d, e Surface and f porous network at $c_{\text {cell }}=6 \mathrm{wt} . \%$

particle), solvent mixing/demixing effects occurring in presence of acetic acid/ethyl acetate/chloroform mixtures may lead to solvent gradient influenced network formation which contributes to the formation of less dense pore structures and less homogenous surfaces.

Summarizing we can say, that we adapted already existing procedures for production of cellulose particles at different cellulose contents in this work, showing the differences in the properties and enhancing the accessible particle sizes. In case of coagulation in $\mathrm{EtAc} / \mathrm{CHCl}_{3} / \mathrm{CH}_{3} \mathrm{COOH}$-bath $\left(c_{\text {cell }}=2 \mathrm{wt} . \%\right)$ we could show, that high surface areas of $400 \mathrm{~m}^{2} / \mathrm{g}$ are achievable due to supercritical drying. Therefore, we have demonstrated the possibility to induce variable pore structures and surface properties in cellulose aerogel particles on the one hand while keeping the specific area on a comparable level on the other hand.
In the next step the coating of the produced aerogel particles was investigated.

Spray coating of aerogel particles

\section{Coating layer properties}

One of the most important characteristics of coating quality is the uniformity of coating material on the particle surface, since non-homogeneous coating results in incomplete protection of the inner porous part and may lead to decreased release control in case of loaded particles. Image analysis via laser microscopy and SEM showed, that the porous structure was completely covered by the coating material and that no cracks and fissures were obtained when working with aerogels with $c_{\text {cell }}=6 \mathrm{wt}$. $\%$ and a shellac content of $c_{\text {shellac }}=20-30 \mathrm{wt} . \%$ in the coating solution (Online Resource 1, Figs. S1-S8). A slight increase in surface 
roughness from $S a=1.7 \pm 0.1 \mu \mathrm{m}$ to $S a=3.6 \pm 0.8$ $\mu \mathrm{m}$ was determined for coated particles of different particle sizes compared to the non-coated species $\left(r_{\mathrm{v} /}\right.$ $\left.\mathrm{m}=2.0 \mathrm{~mL} / \mathrm{g}, c_{\text {shellac }}=20 \mathrm{wt} . \%\right)$, whereas no specific influence of particle size was detected. This increase in surface roughness can be explained by the rapid drying of the solution after coming in contact with the particles, which causes some individual droplets to solidify on the surface before they spread. In contrast, the surface roughness at lower cellulose content does not change significantly after application of coating material $\left(r_{\mathrm{v} / \mathrm{m}}=2.0 \mathrm{~mL} / \mathrm{g}, \quad c_{\text {shellac- }}\right.$ $=20 \mathrm{wt} . \%$ ): on the one hand, the solidified shellac encloses gaps in the surface, and on the other hand the coating material is applied in a non-uniform manner, as shown by microscopic pictures (Online Resource 1, Figs. S9-S11). In addition, parts of the porous structure can be identified which remain uncovered, therefore particles with $c_{\text {cell }}=2 \mathrm{wt}$. $\%$ were only partly coated. The results indicate that initially smoother and non-macroporous aerogel surfaces are important for the formation of uniform coating layers. Therefore, further optimization and quantification of process conditions was carried out at $c_{\text {cell }}=6 \mathrm{wt}$. $\%$. The influence of the shellac concentration on the surface morphology was investigated at two different settings $\left(c_{\text {shellac }}=20 \mathrm{wt} . \%\right.$ and $\left.30 \mathrm{wt} . \%\right)$ and four different ratios between coating solution and bed mass $\left(r_{\mathrm{v} / \mathrm{m}}=1.0-3.5 \mathrm{~mL} / \mathrm{g}\right)$.
The surface roughness increases linearly $\left(\mathrm{R}^{2}=0.985-0.997\right)$ with the amount of applied coating solution (Fig. 5, left), which is a result of the increasing solidification of droplets on particles surface (Fig. 5, right). In addition, the surface roughness is more effected at higher shellac concentrations. This can be explained by the higher viscosity of the spray solution at $c_{\text {shellac }}=30 \mathrm{wt}$. $\%$ which leads to slower spreading of the droplets after hitting the particle surface. In consequence, the liquid evaporates before the droplet has spread completely on the particle surface, and the solid material left behind forms an irregular surface. Due to improved homogeneity of the coating obtained at $c_{\text {shellac }}=20 \mathrm{wt} . \%$, the given shellac concentration was identified as preferable one. Variation of coating layer thicknesses was therefore achieved by changing $r_{v / \mathrm{m}}$ while leaving all other process parameters constant $\left(c_{\text {cell }}=6 \mathrm{wt}\right.$. $\%$, $\left.c_{\text {shellac }}=20 \mathrm{wt} . \%\right)$. Different layer thicknesses were set for particles loaded with vanillin ( $d_{\text {particle- }}$ $=3.06 \mathrm{~mm})$ and non-loaded particles ( $d_{\text {particle- }}$ $=4.37 \mathrm{~mm}$ ) as determined from images analysis of cut open particles (Fig. 6). A clear separation is observed at the interface between the coating material and the inner porous part, which indicates that no coating material and solvent has penetrated into the pore structure during processing (Fig. 6a, b).

The layer thickness increases linearly $\left(\mathrm{R}^{2}=0.975-0.997\right)$ as function of applied coating

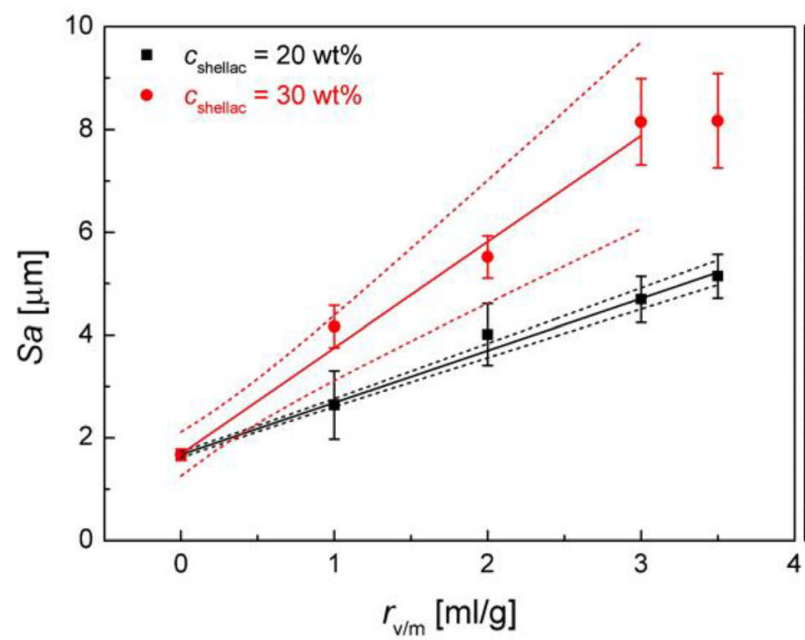

Fig. 5 Left: influence of quantity of the injected solution on surface roughness at different shellac concentrations in the coating solution at constant $c_{\text {cell }}=6 \mathrm{wt} . \%$ and $d_{\text {particle- }}$ $=3.29 \mathrm{~mm}$. Straight lines correspond to linear fits, error bars

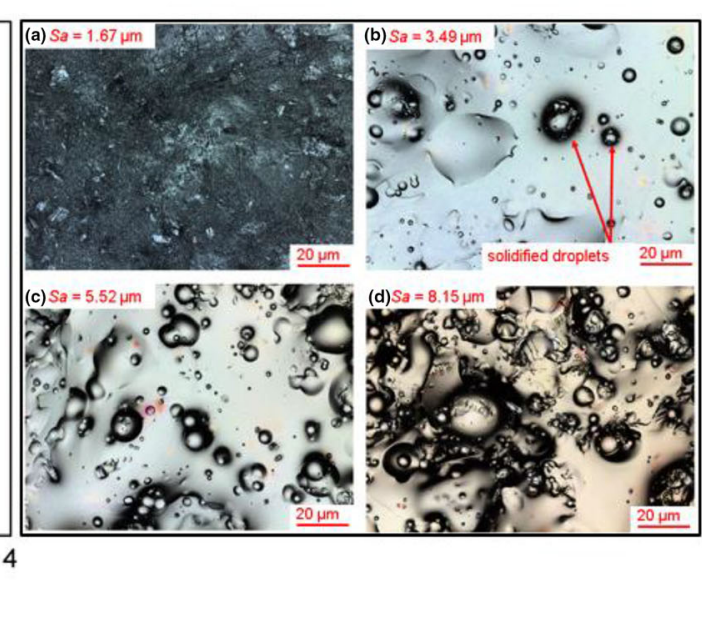

to the standard deviation of six individual measurements. Right panel: images taken by laser microscopy at different roughnesses 


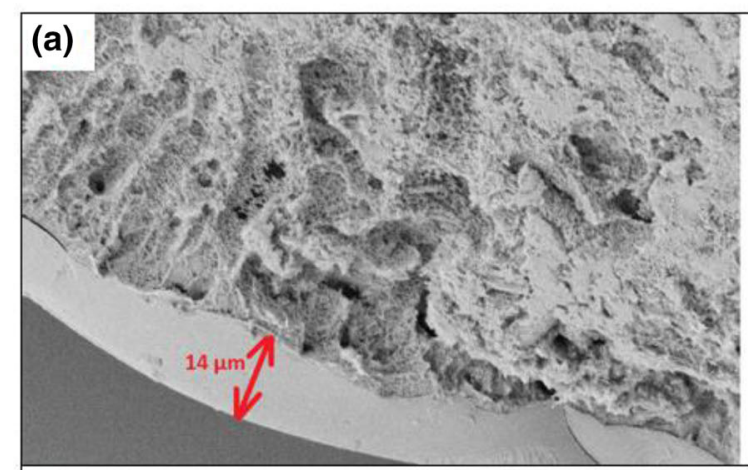

(c)

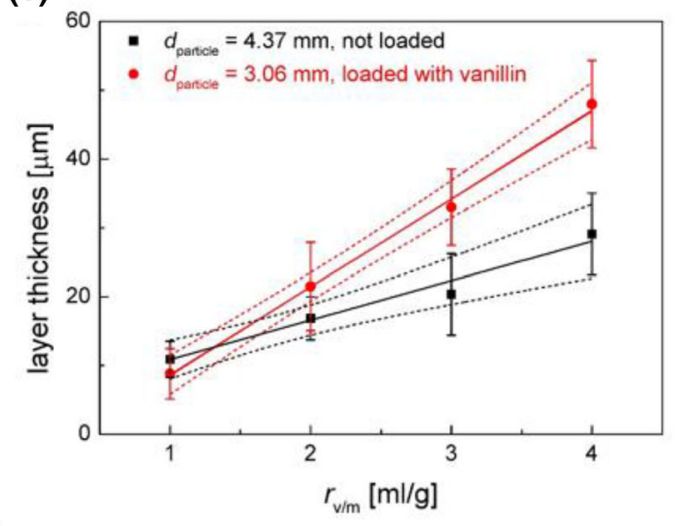

Fig. 6 Exemplary image analysis of a coated particle $\left(c_{\text {cell- }}\right.$ $\left.=6 \mathrm{wt} . \%, d_{\text {particle }}=4.37 \mathrm{~mm}, c_{\text {Shellac }}=20 \mathrm{wt} . \%, r_{\mathrm{v} / \mathrm{m}}=1\right)$ : a scanning electron microscope; b laser microscope. Influence of coating amount on layer thickness; c layer volume per

solution, with higher influence for smaller particles (factor 2.2) (Fig. 6c). This corresponds well to the difference in the overall particle volume (factor 2.1), which was calculated from the particle diameter. In order to directly compare the influence of $r_{\mathrm{v} / \mathrm{m}}$ on the total amount of applied coating per particle for both particle sizes, the coating volume per particle was calculated from the difference of the overall particle volume prior coating and that volume with added layer thickness. All calculations were carried out under the assumption of a perfectly spherical shape for all particles. A similar influence of $r_{\mathrm{v} / \mathrm{m}}$ on the layer volume per particle was determined for both particle species (Fig. 6d), which shows that the spray coating process runs under steady state conditions in the investigated range of particle sizes and densities.

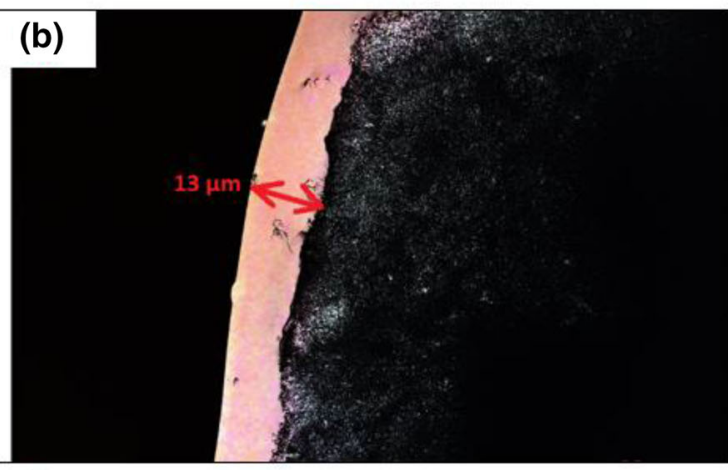

(d)

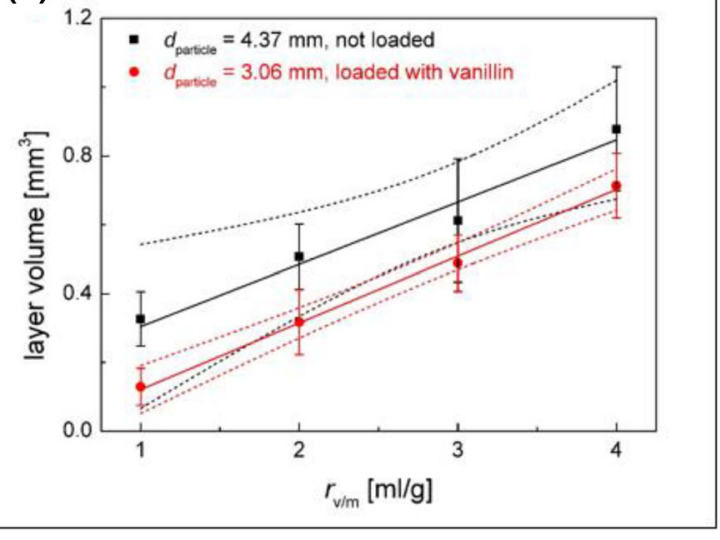

particle. d Straight lines correspond to linear fits, error bars to the standard deviation of image analysis, dashed lines to the $95 \%$ confidence interval

\section{Particle properties}

In addition to changes of surface properties, the coating process can lead to changes in particles size and shape, influencing the bulk density $\rho_{\text {bulk }}$, sphericity $S P H$ and the particle diameter $d_{\text {particle }}$. Changes of the latter in terms of shrinkage is a measure for the pore collapse caused by the coating process. A large value of the shrinkage corresponds to a loss of aerogel specific properties. A comparative study of given properties was carried out for of non-loaded aerogel particles at constant cellulose content $\left(c_{\text {cell }}=6 \mathrm{wt} . \%\right)$ and constant amount of coating solution $\left(r_{\mathrm{v} / \mathrm{m}}=2.0\right)$.

Coating of particles results in an increase of the bulk density $(+22-45 \%)$, whereas the change correlates mainly with the initial particle diameter and results in relatively low overall values of $\rho_{\text {bulk- }}$ $\leq 0.18 \mathrm{~g} / \mathrm{cm}^{3}$ for coated particles (Fig. 7). Only small changes of $S P H$ and $d_{\text {particle }}$ were observed, 


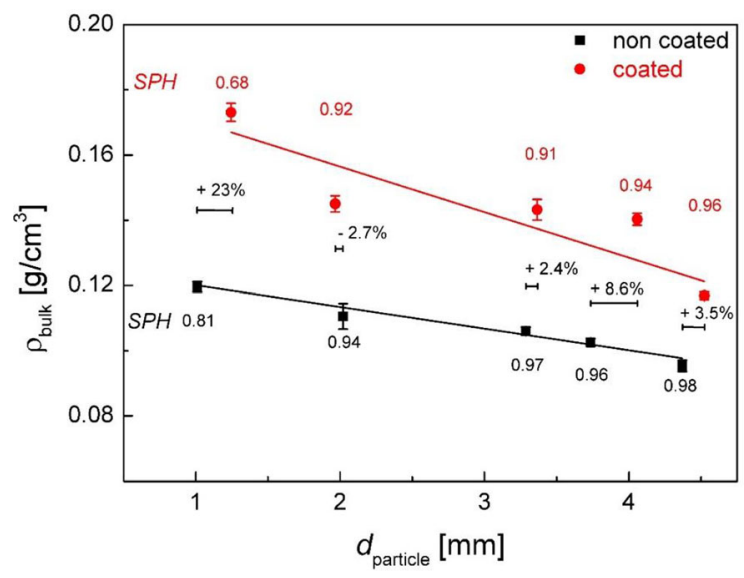

Fig. 7 Influence of spray coating on bulk density and $d_{\text {particle. }}$. Process conditions: $c_{\text {cell }}=6 \mathrm{wt} . \%, r_{\mathrm{v} / \mathrm{m}}=2.0, c_{\text {shellac }}=20 \mathrm{wt} . \%$. Straight lines correspond to the linear fitting, error bars to the standard deviation of bulk density measurements. Bracketed lines symbolize the size change of a given particle species, values in \% correspond to the linear shrinkage decrease (-), or increase $(+)$ in particle size after coating relative to the noncoated species. Numbers without unit correspond to the $\mathrm{SPH}$ value of the according particle species

with exception of particles with the smallest initial values. The results clearly show, that no significant shrinkage occurred during processing, in most cases even slightly higher particle diameters were determined for coated particles. Based on values of layer thicknesses determined by microscopy, an increase in particle diameters in the range of approx. $0.5-4.0 \%$ would have to be expected in case of complete lack of aerogel-shrinkage. A direct quantitative comparison of results regarding changes of particle size obtained via microscopy and particle shape analysis with the Camsizer XT system is however not possible, since the results obtained via Camsizer XT are also influenced by interactions of obtained particle size distributions with particles sphericities, as reported previously (Schroeter et al. 2021). For particles at lower cellulose content of $2 \mathrm{wt} . \%$ and initial particle diameter of $3.18 \mathrm{~mm}$ a significant linear shrinkage of $14.6 \%$ was found under the same process conditions. Obtained shrinkage is however still relatively low when compared to values reported in the literature: spray coating of silica aerogels with waterborne solutions led to an overall linear of shrinkage of up to $75 \%$, and exposure of alginate/starch based aerogels to air humidity to volumetric shrinkage up to approx. 85\% (Alnaief et al. 2012; Antonyuk et al. 2015). Therefore we can conclude, that only partial pore collapse occurred due to ethanol entering the comparatively open surface in case of particles with $c_{\text {cell }}=2 \mathrm{wt}$. \% . Changes of SPH (- 4.2) were in the same range as obtained for particles at higher cellulose content, while the increase in $\rho_{\text {bulk }}$ was comparatively high $(+55 \%)$. Overall, almost no negative influence of the coating process on the aerogels's characteristics was found, especially for particles with high initial sphericity $>0.9$ and a cellulose content of $c_{\text {cell }}=6 \mathrm{wt} . \%$.

Additionally, the influence of the amount of spray solution on particle properties was investigated for particles previously impregnated with vanillin and at a constant initial particle size $\left(d_{\text {particle }}=3.06 \mathrm{~mm}\right)$ in the range of $r_{\mathrm{v} / \mathrm{m}}=1.0-4.0 \mathrm{~mL} / \mathrm{g}$. Only small changes of overall particle sizes (average of $-3.4+-$ $4.4 \%$ ) were found at all values of $r_{\mathrm{v} / \mathrm{m}}$. The bulk density increases as a linear function of $r_{\mathrm{v} / \mathrm{m}}$ $\left(\mathrm{R}^{2}=0.983\right)$ as well as of the calculated layer volume per particle $\left(\mathrm{R}^{2}=0.982\right)$ (Fig. 8). The particle sphericity was not affected significantly.

If the bulk density of coated and loaded particles is considered as the sum of the contributions of the pure aerogel, vanillin introduced by the impregnation and the coating material, the contributions of the individual components can be calculated for different values of $r_{\mathrm{v} / \mathrm{m}}$ (Eq. 4).

$\rho_{\text {bulk,total }}=\rho_{\text {bulk,aerogel }}+\rho_{\text {bulk,vanillin }}+\rho_{\text {bulk,coating }}$

with $\rho_{\text {bulk, total }}=$ total bulk density of impregnated and coated particles, $\rho_{\text {bulk, aerogel }}=$ bulk density of pure aerogel particles in relation to total bulk density, $\rho_{\text {bulk, vanillin }}=$ difference in the bulk density of vanillin loaded particles and pure aerogel particles in relation to the total bulk density, $\rho_{\text {bulk, coating }}=$ difference in the bulk density of coated and non-coated, loaded particles in relation to the total bulk density.

The contribution of the coating material to the total bulk density ranges from $11-24 \%$ and correlates linearly with $r_{\mathrm{v} / \mathrm{m}}\left(\mathrm{R}^{2} 0.981\right)$ (Table 4). Consequently, 


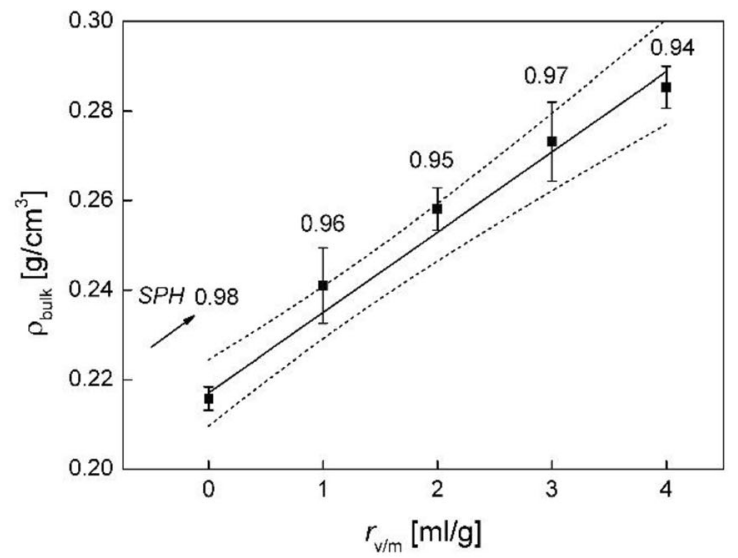

Fig. 8 Bulk density and sphericity auf vanillin loaded particles as function of $r_{\mathrm{v} / \mathrm{m}}$, at constant initial $d_{\text {particle }}(4.37 \mathrm{~mm})$ and $c_{\text {shellac }}(20 \mathrm{wt} . \%)$ (left) and layer volume per particle as function of the bulk density (right). Error bars correspond to the standard

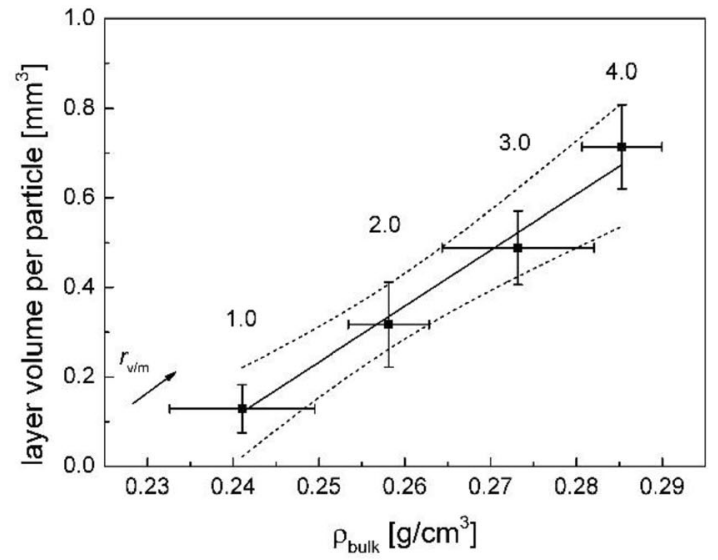

deviation of bulk density measurements, and determination of layer thickness via microscopy. Straight lines correspond to linear fitting, dashed lines to the $95 \%$ confidence interval
Table 4 Fractions of the individual components in the total bulk density of loaded and coated particles

\begin{tabular}{llll}
\hline$r_{\mathrm{v} / \mathrm{m}}(\mathrm{mL} / \mathrm{g})$ & $\rho_{\text {bulk, aerogel }}(\%)$ & $\rho_{\text {bulk, vanillin }}(\%)$ & $\rho_{\text {bulk, coating }}(\%)$ \\
\hline 1.0 & 44.0 & 45.5 & 10.5 \\
2.0 & 41.1 & 42.5 & 16.4 \\
3.0 & 38.8 & 40.2 & 21.0 \\
4.0 & 37.2 & 38.5 & 24.3 \\
\hline
\end{tabular}

bulk density can be used as a direct measure of the overall weight increase of particles during to the coating process.

\section{Specific surface area}

Analysis of cutted aerogel particles via microscopic methods suggested that no change of pore structure and no penetration of coating material into the pores occurred during the processing. At the same time, quantification of the influence of the spray coating process on the microstructure is possible by determination of the specific surface area before and after coating. Since determination of the specific surface area via BET method is based on gravimetric analysis of adsorbed nitrogen on the pores' surfaces, the question arises whether nitrogen can diffuse through the applied shellac layers of whole particles during the measurement process. In order to determine the influence of the outer coating layer, BET results from whole and cut open coated particles were compared at different ratios of $r_{\mathrm{v} / \mathrm{m}}$. The same results for whole and cut particles were obtained for all samples (Online
Resource 1, Fig. S12), therefore the shellac layer had no effect on the measurement results at all ratios of applied coating material.

A systematic study on the effect of $r_{\mathrm{v} / \mathrm{m}}$ and $c_{\text {shellac }}$ was carried out at constant $c_{\text {cell }}=6$ wt. $\%$. Particles showed high surface areas after the coating process which correlated linearly $\left(\mathrm{R}_{\text {non-loaded }}{ }^{2} 0.939, \mathrm{R}_{\text {loaded }}{ }^{2}\right.$ 0.969) with the amount of applied shellac solution (Fig. 9, left).

The loss in specific surface area of loaded particles compared to non-loaded ones is independent of $r_{\mathrm{v} / \mathrm{m}}$ (average of $50.0 \pm 0.8 \%$ ) and can be related to the additional contribution to the overall weight of the sample from vanillin. Furthermore, a general linear relation between the increase in bulk density due to coating and the loss of specific surface area after coating process shows, that changes of the specific surface area result from the weight of coating material (Fig. 9, right). In contrast, loss of specific surface area was found to be 19-32\% higher compared to increase in bulk density for particles with lower cellulose content $\left(c_{\text {cell }}=2 \mathrm{wt} . \%\right)$, which results partly from higher shrinkage under these conditions. Overall, we 


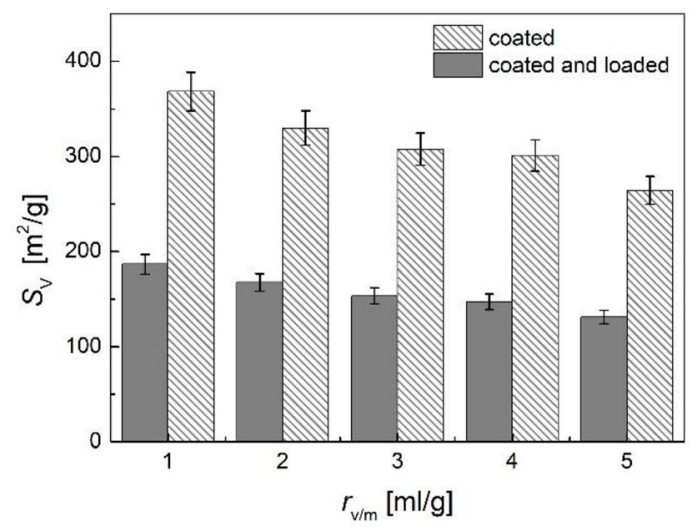

Fig. 9 Specific surface area in dependence of $r_{\mathrm{v} / \mathrm{m}}$ for loaded and non-loaded particles at constant $c_{\text {shellac }}=20 \mathrm{wt} . \%, c_{\text {cell- }}$ $=6 \mathrm{wt} . \%$ and $d_{\text {particle }}=3.3 \mathrm{~mm}$ (left). Error bars correspond to the standard error of BET-results. Decrease of specific surface area due to coating as function of increase in bulk density,

can conclude that the differences in initial surface properties of the particles at different cellulose content are decisive for the quality of the process: The smoother, but open porous surface in form of a skin at $c_{\text {cell }}=6 \mathrm{wt}$. $\%$ led to homogeneous distribution of the coating material on the particles surface without intrusion of coating solution into the pore structure, resulting in a complete preservation of the pore structure.

\section{Release kinetics}

In order to describe the vanillin release from different coated and non-coated aerogel particles, the release data was fitted via a flexible Weibull model approach. The Weibull model has proofed to be suitable for highly correlated non-linear kinetic description of chemical reactions (Schroeter et al. 2019; Manso et al. 2001; Kokkinidou et al. 2014) and follows

$c_{t}=c_{i} \cdot e^{-\left(\frac{t}{\alpha}\right)^{\beta}}$

with $c_{\mathrm{t}}$ being the concentration at time $t, c_{\mathrm{i}}$ is the initial concentration, $\alpha$ is the scale constant and $\beta$ is the shape constant. The quantity $\alpha^{-1}$ is analogous to a rate constant. The shape constant $\beta$ describes mathematically the shape of the reaction profile and is temperature independent, if the reaction mechanism is not related to temperature (Kokkinidou et al. 2014). If $\beta=1$ equation Eq. (5) corresponds to the first-order kinetic model. For description of growth processes the

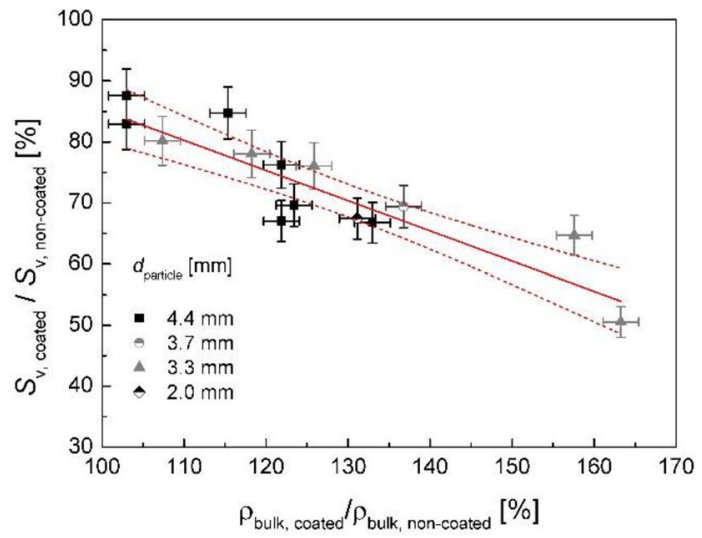

$c_{\text {cell }}=6 \mathrm{wt} . \%, \quad c_{\text {shellac }}=15-30 \mathrm{wt} . \%, \quad d_{\text {particle }}=2.0-4.4 \mathrm{~mm}$. Error bars correspond to the standard error of BET-results ( $y$ axis) and standard deviation of bulk density measurements ( $\mathrm{x}$ axis). Straight line corresponds to linear fitting, dashed lines to the $95 \%$ confidence interval

Weibull model can be adapted (Manso et al. 2001). Equation (5) describes the concentration decrease in the aerogel particles. Since we measured the concentration increase in the aqueous phase, Eq. (5) has to be rewritten by setting $c_{i}$ to $c(t=\infty)=c_{\text {end }}$ and calculating the quantity $c_{\text {end }}-c(t)$. This yields for the concentration of vanillin concentration in the water phase, $c(t)$ :

$c_{t}=c_{\text {end }}-e^{-\left(\frac{t}{\alpha}\right)^{\beta}}$

with $c_{\text {end }}$ being the vanillin concentration in the water phase at the end of the measurement. For individual measurements $c_{\text {end }}$ was set to 1 , i.e. individual measurements were normalized to the concentration at the last measured point. In contrary, in Fig. 10 each data set is compared considering the total amount of vanillin, i.e. $c_{\text {end }}$ corresponds to the absolute amount of vanillin in the aerogel. Fitting was applied with high correlation at all reaction conditions (Table 5).

Without coating the loaded cellulose particles released $50 \%$ of the vanillin in $20.4 \mathrm{~min}$ and $95 \%$ after $110 \mathrm{~min}$ (Fig. 10, left). The release profile of non-coated particles shows, that fast release occurs up to $\sim 60 \%$ release, followed by a slower release phase, which indicates that diffusion control of the process becomes increasingly dominant.

Application of coating led to sustained release control in dependence of the coating layer thickness and leads to increasingly homogenous release profiles. The enhancement of release times is also reflected by 


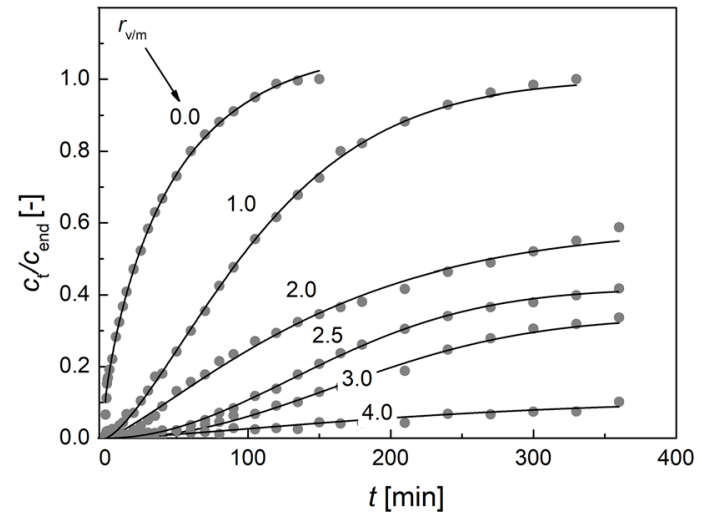

Fig. 10 Release patterns of vanillin from impregnated cellulose aerogel particles $\left(\mathrm{c}_{\text {cell }}=6 \mathrm{wt} . \%, d_{\text {particle }}=3.06 \mathrm{~mm}\right)$ with different coating amounts $\left(\mathrm{c}_{\text {shellac }}=20 \mathrm{wt} . \%\right)$ (left). All data is normalized to $100 \%$ release. The solid lines correspond to Weibull model fitting. Release rate constants and half-life times

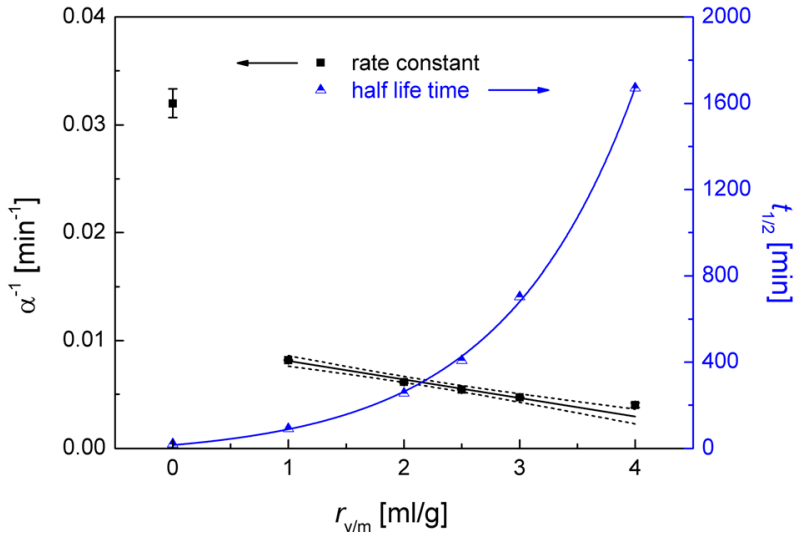

$t_{1 / 2}$ in dependence of $r_{\mathrm{v} / \mathrm{m}}$ (right). Solid lines correspond to data fitting (linear = black, exponential = blue), dashed lines to the 95\% confidence interval. Error bars correspond to the error from individual fitting
Table 5 Fitting of kinetic parameters and rate constants at different ratios of $r_{\mathrm{v} / \mathrm{m}}, c_{\text {cell }}=6 \mathrm{wt} . \%$, $d_{\text {particle }}=3.06 \mathrm{~mm}$, $c_{\text {shellac }}=20 \mathrm{wt} . \%$

\begin{tabular}{llllll}
\hline$r_{\mathrm{v} / \mathrm{m}}(\mathrm{mL} / \mathrm{g})$ & $\mathrm{R}^{2}$ & $\alpha^{-1}\left(\mathrm{~min}^{-1}\right)$ & $\pm \alpha^{-1}\left(\mathrm{~min}^{-1}\right)$ & $\beta(-)$ & $\pm \beta(-)$ \\
\hline 0.0 & 0.989 & $3.2 \times 10^{-2}$ & $1 \times 10^{-3}$ & 0.71 & 0.03 \\
1.0 & 0.999 & $8.2 \times 10^{-3}$ & $4 \times 10^{-5}$ & 1.42 & 0.02 \\
2.0 & 0.994 & $6.1 \times 10^{-3}$ & $1 \times 10^{-4}$ & 1.26 & 0.04 \\
2.5 & 0.998 & $5.4 \times 10^{-3}$ & $4 \times 10^{-5}$ & 2.02 & 0.03 \\
3.0 & 0.995 & $4.7 \times 10^{-3}$ & $5 \times 10^{-5}$ & 2.14 & 0.06 \\
4.0 & 0.921 & $4.0 \times 10^{-3}$ & $2 \times 10^{-4}$ & 1.4 & 0.1 \\
\hline
\end{tabular}

the rate constant $\alpha^{-1}$, which decreases by $74 \%$ at $r_{\mathrm{v} /}$ $\mathrm{m}=1.0 \mathrm{~mL} / \mathrm{g}$ compared to the release from the uncoated species and correlates linearly $\left(\mathrm{R}^{2} 0.985\right)$ with the coating amount (Fig. 10, right). While the half-life times of the release $t_{1 / 2}$ could be determined directly for $r_{\mathrm{v} / \mathrm{m}} \leq 2 \mathrm{~mL} / \mathrm{g}$, half-life times for $r_{\mathrm{v} /}$ $\mathrm{m}>2 \mathrm{~mL} / \mathrm{g}$ were calculated by linear extrapolation of the raw data under assumption of intactness of the coating over the extrapolated time period. A broad range of total release times is accessible within the investigated range for vanillin, which is reflected by the exponential increase of $t_{1 / 2}$ as function of added shellac solution $\left(\mathrm{R}^{2}\right.$ 0.999) (Fig. 10, right). Mechanistically, drug release in aerogels depends on several factors: the rate determining step in the release of vanillin from non-coated cellulose aerogel particles can expected to be the transport of the dissolved drug from the pores and particles external surface to the water phase, which tend to be fast, since they depend on the hydration and dissolution of a hydrophilic drug from a hydrophilic aerogel (García-González et al.
2021). In addition to wetting and hydration, overall drug release rates from aerogels can also be influenced by erosion of the gel matrix, whereas biopolymer aerogels swell and collapse in water, which results in the formation of hydrogel like particles (GarcíaGonzález et al. 2021; Kéri et al. 2020). Since the shellac layer is practically insoluble in non-alkaline aqeous media, the rate of vanillin permeation in the given case should be proportional to both: to the extent of the hydration and the thickness of the coating layer, the latter being reflected by the rate constants (Table 5; Fig. 10). Furthermore, coating as well as particles were (optically) intact after the measurements, which indicates that the shellac coating may also inhibit possible erosion of aerogel particles, which are less stable then cellulose based materials. 


\section{Conclusions}

It was firstly shown that the spouted bed technology is a suitable method for coating of low density, hydrophilic and open porous cellulose aerogel materials with ethanolic shellac solutions. On contrast to silica aerogels, no additional protective layer is required for cellulose aerogels. Suitable routes for production of cellulose aerogels with different densities and high sphericities were identified, including different coagulation strategies to tune aerogel particles' surface and textural properties. Specific surface areas in the range of $\sim 400-450 \mathrm{~m}^{2} / \mathrm{g}$ were obtained using supercritical drying technology. By analysis of specific surface area and bulk densities before and after coating, it was unambiguously demonstrated that the inner porous structure of aerogels remains intact during the coating process. A clear border between coating layer material and pore structure could be identified via microscopic methods. In consequence it can be concluded that the drying of the sprayed solution on the particle surface was faster than its penetration into the pores, which was one of the targets of this work.

It was shown that increase of the surface roughness resulted from the fast drying of droplets on the particles surface, with higher changes of roughness being obtained at higher amounts of shellac solution and shellac concentrations. The precise setting of coating layer thickness was possible due to variation of the ratio between sprayed coating solution and number of processed particles. Low initial roughness and homogeneities are decisive for the quality of the coating process: particles with a cellulose content of $6 \mathrm{wt} . \%$ and a smooth surface showed complete enclosed coating layers, while surfaces with initial defects in from of gaps and higher roughness at lower cellulose content ( 2 wt.\%) led to incomplete coating layers, with parts of the open porous structure remaining un-covered. Stable fluidization without breakage or agglomeration of the particles was achieved for particles of different densities and a broad range of particle sizes from $\sim 1.1$ to $4.4 \mathrm{~mm}$, as reflected by the analytics of the size and shape prior and after coating.

Impregnation of the particles with vanillin in presence of supercritical $\mathrm{CO}_{2}$ resulted in loaded particles with intact pore structure. It was demonstrated that coating of vanillin-loaded particles with different layer thicknesses allows to control the release of vanillin in aqueous environment in a broad range of release times.

While the shellac coating enables controlled release from the inner porous part on the one hand, it serves also as a protection layer for the pore structure against external influences (e.g. humidity) on the other hand, therefore enhancing the aerogels shelf life. The combination of protection and controlled release enhances the applicability and tuneability of biopolymer aerogels, especially as drug delivery excipients in the pharmaceutical field and as part of digestible or injectable formulations.

While the given showcase demonstrates the applicability of spouted bed spray coating for the creation of biocompatible and edible aerogel systems, further studies are necessary to show the transferability of this method to other hydrophilic biopolymer aerogels (e.g. alginate) with low density and variable surface properties. Thus, in our future work different aspects of shellac coating in regards to its drying kinetics, film formation at different process conditions and coating uniformity on other biopolymer aerogels, will be investigated.

Author contributions The manuscript was written through contributions of all authors. All authors have given approval to the final version of the manuscript.

Funding Open Access funding enabled and organized by Projekt DEAL. The authors wish to acknowledge support for this research received from the German Research Foundation (DFG) under the project SM 82/18-1 and HE 4526/24-1.

Data availability Additional Data (Table S1, Figs. S1-S12) is reported in the electronic supplementary data.

\section{Declaration}

Conflict of interest All authors declare that they have no conflict of interest.

Human and animal rights This manuscript does not contain any studies with human participants or animals performed by any of the authors.

Open Access This article is licensed under a Creative Commons Attribution 4.0 International License, which permits use, sharing, adaptation, distribution and reproduction in any medium or format, as long as you give appropriate credit to the original author(s) and the source, provide a link to the Creative Commons licence, and indicate if changes were made. The images or other third party material in this article are 
included in the article's Creative Commons licence, unless indicated otherwise in a credit line to the material. If material is not included in the article's Creative Commons licence and your intended use is not permitted by statutory regulation or exceeds the permitted use, you will need to obtain permission directly from the copyright holder. To view a copy of this licence, visit http://creativecommons.org/licenses/by/4.0/.

\section{References}

Akgün IS, Erkey C (2019) Investigation of hydrodynamic behavior of alginate aerogel particles in a laboratory scalewurster fluidized bed. Molecules 24(16):1-18. https:// doi.org/10.3390/molecules24162915

Alnaief M, Antonyuk S, Hentzschel CM, Leopold CS, Heinrich S, Smirnova I (2012) A novel process for coating of silica aerogel microspheres for controlled drug release applications. Microp Mesop Mater 160:167-173. https://doi.org/ 10.1016/j.micromeso.2012.02.009

Antonyuk S, Heinrich S, Smirnova I (2012) Discrete element study of aerogel particle dynamics in a spouted bed apparatus. Chem Eng Technol 35(8):427-1434. https://doi.org/ 10.1002/ceat.201200083

Antonyuk S, Heinrich S, Ershova A (2013) DEM study of fluidized bed dynamics during particle coating in a spouted bed apparatus. In: 10th int conf circ fluid beds fluid technol CFB-10 RP7(1), pp 47-65

Antonyuk S, Heinrich S, Gurikov P, Raman S, Smirnova I (2015) Influence of coating and wetting on the mechanical behaviour of highly porous cylindrical aerogel particles. Powder Technol 285:34-43. https://doi.org/10.1016/j. powtec.2015.05.004

Baudron V, Gurikov P, Smirnova I, Whitehouse S (2019) Porous starch materials via supercritical-and freeze-drying. Gels 5(1):9-13. https://doi.org/10.3390/gels5010012

Bian H, Shao Z, Li L, Liu J, Chen K, Zhang X (2020) Preparation of diameter-controlled cellulose aerogel spheres via atomization method and their load performance. Macromol Mater Eng 2000243:1-8. https://doi.org/10.1002/mame. 202000243

Budtova T (2019) Cellulose II aerogels: a review. Cellulose 26(1):81-121. https://doi.org/10.1007/s10570-018-2189-

García-González CA, Alnaief M, Smirnova I (2011) Polysaccharide-based aerogels promising biodegradable carriers for drug delivery systems. Carbohydr Polym 86(4):1425-1438. https://doi.org/10.1016/j.carbpol.2011. 06.066

García-González CA, Sosnik A, Kalmár J, De Marco I, Erkey C, Concheiro A, Alvarez-Lorenzo C (2021) Aerogels in drug delivery: from design to application. J Control Release 332:40-63. https://doi.org/10.1016/j.jconrel.2021.02.012

Goslinska M, Selmer I, Kleemann C, Kulozik U, Smirnova I, Heinrich S (2019) Novel technique for measurement of coating layer thickness of fine and porous particles using focused ion beam. Particuology 42:190-198. https://doi. org/10.1016/j.partic.2018.03.002

Hult EL, Lotti M, Lenes M (2010) Efficient approach to high barrier packaging using microfibrillar cellulose and shellac. Cellulose 17(3):575-586. https://doi.org/10.1007/ s10570-010-9408-8

Jones DM (1985) Factors to consider in fluid-bed processing. Pharm Technol 1:1-7

Kéri M, Forgács A, Papp V, Bányai I, Veres P, Len A, Dudás Z, Fábián I, Kalmár J (2020) Gelatin content governs hydration induced structural changes in silica-gelatin hybrid aerogels-implications in drug delivery. Acta Biomater 105:131-145. https://doi.org/10.1016/j.actbio.2020.01.016

Kokkinidou S, Floros JD, Laborde LF (2014) Kinetics of the thermal degradation of patulin in the presence of ascorbic acid. J Food Sci 79(1):108-114. https://doi.org/10.1111/ 1750-3841.12316

Lee BB, Ravindra P, Chan ES (2013) Size and shape of calcium alginate beads produced by extrusion dripping. Chem Eng Technol 36(10):1627-1642. https://doi.org/10.1002/ceat. 201300230

Liebner F et al (2009) Cellulosic aerogels as ultra-lightweight materials. Part 2: synthesis and properties. Holzforschung 63(1):3-11. https://doi.org/10.1515/HF.2009.002

Manso MC, Oliveira FAR, Oliveira JC, Frías JM (2001) Modelling ascorbic acid thermal degradation and browning in orange juice under aerobic conditions. Int J Food Sci Technol 36(3):303-312. https://doi.org/10.1046/j.13652621.2001.t01-1-00460.x

Mehling T, Smirnova I, Guenther U, Neubert RHH (2009) Polysaccharide-based aerogels as drug carriers. J Non Cryst Solids 355(50-51):2472-2479. https://doi.org/10. 1016/j.jnoncrysol.2009.08.038

Pantić M, Knez Ž, Novak Z (2016) Supercritical impregnation as a feasible technique for entrapment of fat-soluble vitamins into alginate aerogels. J Non Cryst Solids 432:519-526. https://doi.org/10.1016/j.jnoncrysol.2015. 11.011

Rojas-Ávila A, Pimentel-Rodas A, Rosales-García T, DávilaOrtiz G, Galicia-Luna LA (2016) Solubility of binary and ternary systems containing vanillin and vanillic acid in supercritical carbon dioxide. J Chem Eng Data 61(9):3225-3232. https://doi.org/10.1021/acs.jced. 6b00322

Rothberg HS, Pietsch S, Schneider GA, Heinrich S (2020) Fabrication of highly filled composites with an innovative miniaturized spouted bed. Processes 8(5):1-11. https://doi. org/10.3390/PR8050521

Sandhya (2010) Modified atmosphere packaging of fresh produce: current status and future needs. LWT Food Sci Technol 43(3):381-392. https://doi.org/10.1016/j.lwt. 2009.05.018

Schroeter B, Bettermann S, Semken H, Melchin T, Weitzel HP, Pauer W (2019) Kinetic description of ascorbic acid decomposition in redox initiator systems for polymerization processes. Ind Eng Chem Res 58(29):12939-12952. https://doi.org/10.1021/acs.iecr.9b00710

Schroeter B, Yonkova VP, Niemeyer NAM, Jung I, Preibisch I, Gurikov P, Smirnova I (2021) Cellulose aerogel particles: control of particle and textural properties in jet cutting process. Cellulose 28(1):223-239. https://doi.org/10.1007/ s10570-020-03555-2

Smirnova I, Gurikov P (2017) Aerogels in chemical engineering: Strategies toward tailor-made aerogels. Annu Rev 
Chem Biomol Eng 8:307-334. https://doi.org/10.1146/ annurev-chembioeng-060816-101458

Subrahmanyam R, Gurikov P, Dieringer P, Sun M, Smirnova I (2015) On the road to biopolymer aerogels - dealing with the solvent. Gels 1(2):291-313. https://doi.org/10.3390/ gels1020291

Ulker Z, Erkey C (2014) An emerging platform for drug delivery: aerogel based systems. J Control Release 177(1):51-63. https://doi.org/10.1016/j.jconrel.2013.12. 033

Veres P et al (2018) A redox strategy to tailor the release properties of $\mathrm{Fe}(\mathrm{III})$-alginate aerogels for oral drug delivery. Carbohydr Polym 188:159-167. https://doi.org/10. 1016/j.carbpol.2018.01.098
Volkert B, Wolf B, Fischer S, Li N, Lou C (2009) Application of modified bead cellulose as a carrier of active ingredients. Macromol Symp 280(1):130-135. https://doi.org/10.1002/ masy.200950615

Zeng B, Wang X, Byrne N (2020) Cellulose beads derived from waste textiles for drug delivery. Polymers. https://doi.org/ $10.3390 /$ polym 12071621

Publisher's Note Springer Nature remains neutral with regard to jurisdictional claims in published maps and institutional affiliations. 